\title{
Functioning pituitary tumours: Hints from the skin
}

\author{
Florica Sandru' ${ }^{1,2}$, Ana Valea ${ }^{3,4}$, Simona Elena Albu ${ }^{1,5}$, Mihai Cristian Dumitrascu, ${ }^{1,5}$, \\ Constantin Dumitrache ${ }^{1,6}$, Ana Maria Alexandra Stanescu', Mara Carsote ${ }^{1,6}$ \\ 1"Carol Davila" University of Medicine and Pharmacy, Bucharest, Romania \\ Elias Emergency University Hospital, Bucharest, Romania \\ ${ }^{3}$ Clinical County Hospital, Cluj-Napoca, Romania \\ 4"Iuliu Hatieganu" University of Medicine and Pharmacy, Cluj-Napoca, Romania \\ ${ }^{5}$ Emergency University Hospital, Bucharest, Romania \\ 6"C.I. Parhon" National Institute of Endocrinology, Bucharest, Romania
}

\begin{abstract}
We introduce dermatological aspects from an endocrine point of view related to pituitary tumours that display active secretor activity. This is a short literature review. 40 papers are cited including narrative reviews and original studies. Acromegaly: GH overproduction causes the thickening of the skin and swelling of the soft tissues in addition to the enlargement of extremities (like nose, hands, feet, jaw), coarsening of facial features (as front head and naso-labial folds), excessive sweating, exaggerate skin wrinkles, oily skin, and acrochordons. Cushing's disease: cortisol overproduction has a severe protein catabolic effect at skin with collagen network disruption while immune effect of hypercortisolemia induces chronic skin infections and difficulties in wound healing. In females, consecutive androgens excess induces acne, hirsutism, and androgens-related alopecia. The classical phenotype includes: fragile skin or skin atrophy, red/purple striae, easy bruising, facial plethora. Skin changes represent the window to pituitary tumours for clinicians of different specialities, therefore contributing to final diagnosis of endocrinopathies.
\end{abstract}

Keywords: dermatology, acromegaly, Cushing's disease, diabetes mellitus, cutaneous

\author{
Abbreviations \\ $\mathrm{ACTH}=$ adrenocorticotropic hormone \\ $\mathrm{CNC}=$ Carney complex \\ FIPA $=$ familial isolated pituitary adenomas \\ $\mathrm{GH}=$ growth hormone
}

\section{INTRODUCTION}

Pituitary adenomas represent a large, heterogeneous field of interest $(1,2)$. They may be functionally inactive, in which case the detection is based on mass effects like endocrine associated complications (pituitary insufficiency or diabetes insipidus), neurological, ophthalmic, and radiological complications or they are incidentally detected (with a prevalence of one in every ten adult persons based on some statistics) $(3,4,5)$. The endocrine panel is pathologically reflected in tumour derivate activity as: GH (growth hormone) production by a somatotropinoma (the associated disease is acro-
MEN1 = multiple endocrine neoplasia type 1

$\mathrm{PRL}=$ prolactin

$\mathrm{TSH}=$ thyroid stimulating hormone

megaly), Prolactin (PRL) secretion by a prolactinoma, ACTH (adrenocorticotropic hormone) excess by a corticotropinoma causing Cushing's disease, thyrotropinoma - associated TSH (thyroid stimulating hormone or thyrotropin) excessive activity that induces secondary hyperthyroidism as well as gonadotropinoma underlying gonadotropes overproduction $(1,2)$.

Pituitary adenomas of any type have a prevalence of $1 / 865$ up to 2,688 adults (1). Microadenomas have less than 1 centimetre $(\mathrm{cm})$ while macroadeomas' size is more than $1 \mathrm{~cm}$ cut off for at least one diameter $(1,2)$. The most interesting statistical data regarding the field are: $50 \%$ of hypo- 
physeal tumours are microadenomas; $33-66 \%$ are prolactinomas of any size; $8-16 \%$ of all are GH-producing pituitary tumours; $1 \%$ are thyrotropinomas; $15-54 \%$ of pituitary neoplasia are clinically non-functioning adenomas (a prevalence of 7-41.3 in 100,000 persons) $(1,2)$. On the other hand, Cushing's syndrome according to an unselected retrospective cohort published in 2019 that followed subjects from 2002 to 2017 showed: the incidence of endogenous Cushing's syndrome is 3.2/one million persons/year, respective $1.5 /$ one million persons/year for Cushing's disease, 0.8/one million people/year for ectopic Cushing's syndrome, 0.7/ one million persons/year for non-cancer adrenal Cushing's syndrome, and 0.2 cases/one million persons/year for adrenal carcinoma (6).

\section{AIM}

We introduce some dermatological aspects from an endocrine point of view related to pituitary tumours that display active secretor activity.

\section{METHOD}

This is a short literature review. The research starts from Pub Med database. 40 papers are cited including narrative reviews and original studies. The criteria of selection are based on clinical relevance from both an endocrine and a dermatological point of view.

\section{GENERAL PRESENTATION}

\section{Acromegaly}

GH overproduction causes, among glucose anomalies, high cardiovascular risk, organomegaly, colonic polyps, respiratory and sleep disturbances, etc, the thickening of the skin and swelling of the soft tissues in addition to the enlargement of extremities (like nose, hands, feet, jaw), coarsening of facial features (as front head and naso-labial folds), excessive sweating, exaggerate skin wrinkles, oily skin, and acrochordons $(7,8)$ (Figure 1). The underling modifications are dermal glycosaminoglycan deposits and associated oedema $(7,8,9)$. The specific hormonal assays confirm the GH-IGF1 excess as a specific cause while $95 \%$ of cases are attributed to a pituitary somatotropinoma $(7,8)$. The disease equally affects both sex, typically in adults over 40 years $(5 \%$ of cases debut under 20 years old and open cartilages involve gigantism due to $\mathrm{GH}$ specific action) $(7,8)$. The clinical recognition of the condition with the full blown phenotype usually involves a prior decade of biochemically active and clinically asymptomatic (or mild symptomatic) pituitary tumour $(7,8,9)$. The progressive onset of acromegaly features delay the presentation and less than $15 \%$ of patients are actually admitted only for this aspect, while the other $85 \%$ are referred for systemic complications $(8,9,10)$. Skin changes in acromegaly are explained mostly by GH receptors in all skin cells (10). Another pathogenic loop includes IGF1 receptors that are only expressed in a few cells - epidermal keratinocytes (10). The correction of GH-IGF1 excess allows the remission of soft tissue anomalies like puffy hands and feet while bone anomalies are irreversible $(8,9,19)$.

Pachydermoperiostosis may mimic acromegaly but it represents a rare autosomal recessive disorder of prostaglandin E2 excess, not GH-IGF1 (11). Also, the skin and bone/join anomalies may be mistaken as primary (idiopathic or underlying gene mutations like recently identified SLCO2A1) or secondary hypertrophic osteoarthropathy (as seen in lung cancer) (12).

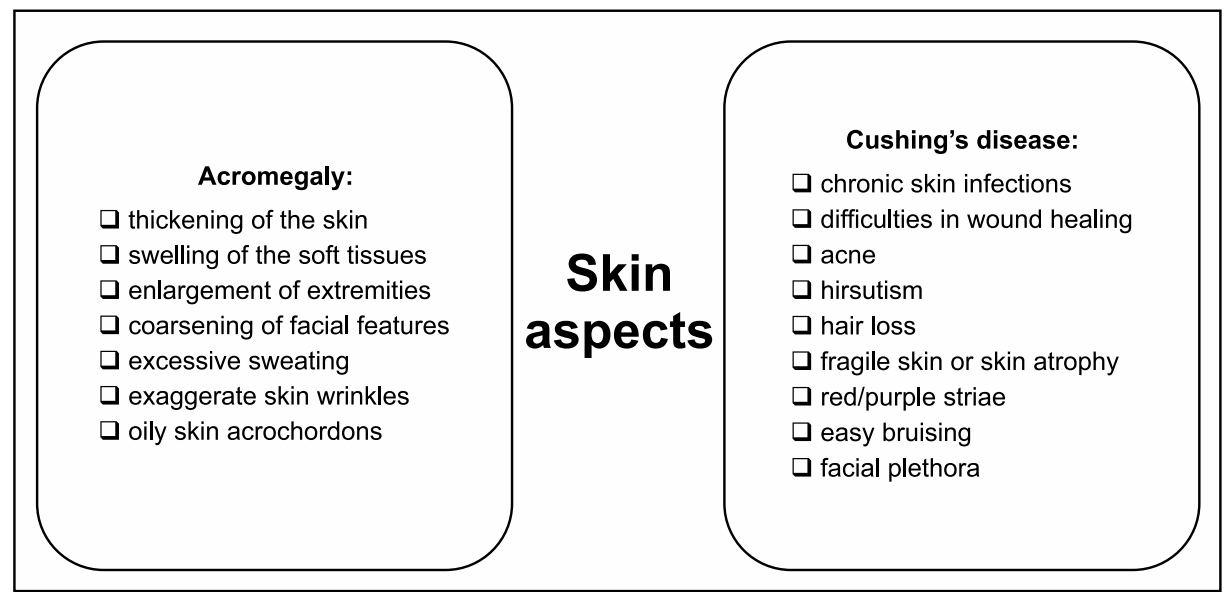

FIGURE 1. Skin hallmarks in somatotropinomas and corticotropinomas 


\section{Cushing's disease}

The endogenous chronic excess of glucocorticoids causes dramatic changes of the clinical appearance in addition to severe cardio-metabolic anomalies like high blood pressure, diabetes mellitus, obesity, osteoporosis and fragility fractures, proximal myopathy, hyperlypemia, depression etc. $(7,13)$. The delay of diagnosis varies, a median of 2 years have been reported $(13,14)$. The pituitary tumour removal is the first line of therapy but alternatives like pasireotide, cabergoline, pituitary radiotherapy, bilateral adrenalectomy, etc. are also needed in many cases with only a partial remission of co-morbidities $(15,16)$.

Cortisol overproduction has a severe protein catabolic effect at the level of skin with collagen network disruption while immune effect of hypercortisolemia induces chronic skin infections and difficulties in scars repair or wound healing $(17,18)$. In females, consecutive androgens excess induces acne, hirsutism, and even hair loss (androgens-related alopecia) (19). The classical phenotype includes: fragile skin or skin atrophy, red/purple striae, easy bruising, facial plethora (which are not typical in paediatric onset of Cushing's disease where obesity and growth retardation are the hallmark) $(13,18)$ (Figure 1).

\section{Other pituitary tumours}

In prolactinomas (the most frequent secretor tumour at the level of pituitary gland), as also in gonadotropinomas (with an exceptional prevalence), there are no skin anomalies that may be considered highly specific $(20,21)$. The high prolactin-related central hypogonadism may be associated with anaemia and thus a pale skin may be seen while galactorrhea at both sex and gynecomastia in males are milestones for clinical diagnosis $(20,21)$. Central hyperthyroidism due to a thyrotropinoma causes hyperhidrosis and rarely onycholysis in association with cardiovascular anomalies or the clinical presentation is dominated by compressive symptoms of the pituitary tumour itself (22).

\section{DISCUSSION}

We discuss the main conditions that are associated with functioning pituitary tumours: on one hand, there are the effects of the hypophyseal mass like central hypogonadism, hypocortisolemia, and hypothyroidism with potential skin manifestations and, on the other hand, secondary diabetes mellitus is registered especially in acromegaly and Cush- ing's disease with a large area of dermatological complications $(17,23)$. Moreover, pituitary neoplasia associated with genetic syndrome involve multiple co-morbidities and some of them have distinct tegumentary aspects.

\section{Associated conditions: Pituitary insufficiency}

The typical tumour-related pituitary mass effects are: headache, visual field anomalies, diabetes insipidus and hypopituitarism that are registered in macroadenomas regardless their endocrine activity (24). Hypothyroidism is manifested with dry skin, fragile hair, cold intolerance; secondary chronic adrenal insufficiency exhibits pale skin (opposite to hyper-pigmentation due to high ACTH in primary adrenal insufficiency) (25).

\section{Associated conditions: Diabetes mellitus}

Diabetes mellitus associated with endocrine conditions involves a large area of complications including the skin: necrobiosis lipoidica diabeticorum, difficulties in wound healings, persistent infections, diabetic dermopathy (aggravated by diabetic neuropathy or vasculopathy/angiopathy), pruritus, acanthosis nigricans as sign of insulin resistance $(7,26,27)$. Persistent high glucose affects each skin cell (27). Diabetes therapy like insulin may cause lypoatropy etc. (27).

The control of underling hormonal excess like $\mathrm{GH}$ or ACTH/cortisol is usually associated with an improvement of glucose profile, and even in some cases with a complete remission of diabetes $(28,29)$. In acromegaly - associated diabetes the therapy with somatostatin analogues like those of first generation octreotide and lanreotide may induce a worsening of glucose metabolism which actually is more frequent under second line somatostatin analogue pasireotide LAR $(28,30)$. Subcutaneous pasireotide is also a therapeutic option in Cushing's disease and it exhibits the same side effect regarding glycaemia anomalies and long term complications including local skin changes at the site of the injection (30).

\section{Syndromic context of pituitary tumours: MEN 1 syndrome}

GH-producing pituitary tumours with familial pattern are either syndromic like multiple endocrine neoplasia (MEN) type 1 or 4, Carney complex (CNC) or McCune-Albright syndrome, either isolated forms like familial isolated pituitary adenomas (FIPA) $(31,32)$. MEN1 caused by inactivating mutations of menin gene includes neuroendo- 
crine tumours, prolactinomas, and primary hyperparathyroidism $(33,34)$. MEN4 underlines $C D K N 1 B$ gene inactivation and it includes somatotropinomas, primary pigmented nodular adrenocortical disease and myxomas at different levels as well as lentigines (meaning spotty skin pigmentation) $(31,35)$.

\section{Syndromic context of pituitary tumours: Carney complex}

CNC (mutations of PRKARIA gene) includes primary pigmented nodular adrenal masses, adrenocortical carcinoma, myxomas of different locations, acromegaly, neoplasia at breast or thyroid and skin anomalies like lentiginosis, pigmentation of different patterns and melanocytic schwannoma $(36,37,38)$. The rare condition is autosomal domi-

\section{REFERENCES}

1. Molitch ME. Diagnosis and Treatment of Pituitary Adenomas: $A$ Review. JAMA. 2017; 317(5):516-524.

2. Ntali G, Wass JA. Epidemiology, clinical presentation and diagnosis of non-functioning pituitary adenomas. Pituitary. 2018; 21(2):111-118.

3. Gheorghisan-Galateanu AA, Carsote M, Valea A. Incidentaloma: From general practice to specific endocrine frame. J Pak Med Assoc. 2017; 67(6):917-922.

4. Gheorghiu M, Hortopan D, Dumitrascu A, Caragheorgheopol A, Stefanescu A, Trifanescu R, Niculescu D, Baciu I, Carsote M, Poiana C, Badiu C, Coculescu M. Age-related endocrine tumors: nonfunctioning adrenal tumors as compared to pituitary adenomas. Acta Endocrinologica, 2009; V(3):371-384

5. Carsote M, Chirita C, Dumitrascu A, Fica S, Poiana C. Pituitary incidentalomas -How often is too often? Journal of Medicine and Life, 2009; 2(1):92-97.

6. Wengander S, Trimpou P, Papakokkinou E, Ragnarsson The incidence of endogenous Cushing's syndrome in the modern era. Clin Endocrinol (Oxf). 2019; 91(2):263-270.

7. Lause M, Kamboj A, Fernandez Faith E. Dermatologic manifestations of endocrine disorders. Transl Pediatr. 2017;6(4):300-312.

8. Vilar L, Vilar CF, Lyra R, Lyra R, Naves LA. Acromegaly: clinical features at diagnosis. Pituitary. 2017; 20(1):22-32.

9. Degirmentepe EN, Gungor S, Kocaturk E, Kiziltac U, Adas M, Ozekinci S, Khachemoune A. Dermatologic manifestations of acromegaly: A case in point and a focused review. Dermatol Online J. 2017; 23(8).

10. Kanaka-Gantenbein C, Kogia C, Abdel-Naser MB, Chrousos GP. Skin manifestations of growth hormone-induced diseases. Rev Endocr Metab Disord. 2016; 17(3):259-267.

11. Lause M, Kamboj A, Fernandez Faith E. Dermatologic manifestations of endocrine disorders. Transl Pediatr. 2017;6(4):300-312.

12. Mangupli R, Daly AF, Cuauro E, Camperos P, Krivoy J, Beckers A. Primary hypertrophic osteoarthropathy due to a novel SLCO2A1 mutation masquerading as acromegaly. Endocrinol Diabetes Metab Case Rep. 2017; 2017.

13. Braun LT, Riester A, Oßwald-Kopp A, Fazel J, Rubinstein G, Bidlingmaier M, Beuschlein F, Reincke M. Toward a Diagnostic Score in Cushing's Syndrome. Front Endocrinol (Lausanne). 2019; 10:766.

14. Kreitschmann-Andermahr I, Psaras T, Tsiogka M, Starz D, Kleist B, Siegel S, Milian M, Kohlmann J, Menzel C, Führer-Sakel D, Honegger J, Sure U, Müller O, Buchfelder M. From first symptoms to final diagnosis of Cushing's disease: experiences of 176 patients. Eur $J$ Endocrinol. 2015; 172(3):285-9. nant and it seems that somatotropinomas as usually microadenomas opposite to general aspects (38).

\section{Syndromic context of pituitary tumours: McCune Albright syndrome}

The syndrome includes a part from acromegaly, fibrous dysplasia of bone, and skin aspects as: caféau-lait spots of different sizes, and hyperpigmented areas $(39,40)$. The disease is caused by activating mutations of GNAS gene $(39,40)$.

\section{CONCLUSION}

Skin changes represent the window to pituitary tumours for clinicians of different specialities, therefore contributing to final diagnosis of endocrinopathies.

Conflict of interest: none declared Financial support: none declared

15. Poiana C, Chirita C, Carsote M, Hortopan D, loachim D, Corneci CM, Stanescu B. Adrenal and Pituitary Incidentalomas in a Case of Cushing's Syndrome. Chirurgia 2013; 6(108):886-891.

16. Paduraru DN, Nica A, Carsote M, Valea A. Adrenalectomy for Cushing's syndrome: Do's and don'ts. Journal of Medicine and Life. 2016; 4(9):334-341.

17. Pivonello R, Isidori AM, De Martino MC, Newell-Price J, Biller BM, Colao A. Complications of Cushing's syndrome: State of the art. Lancet Diabetes Endocrinol. 2016; 4(7):611-29.

18. Stratakis CA. Skin manifestations of Cushing's syndrome. Rev Endocr Metab Disord. 2016; 17(3):283-286.

19. Lefkowitz EG, Cossman JP, Fournier JB. A Case Report of Cushing's Disease Presenting as Hair Loss. Case Rep Dermatol. 2017; 9(1): 45-50.

20. Glezer A, Bronstein MD. Prolactinomas. Endocrinol Metab Clin North Am. 2015; 44(1):71-8.

21. Poiana C, Chirita C, Carsote M, Hortopan D, Goldstein A. Galactocele and prolactinoma - A pathogenic association? Maturitas. 2009; 62(1):98-102

22. Amlashi FG, Tritos NA. Thyrotropin-secreting pituitary adenomas: Epidemiology, diagnosis, and management. Endocrine. 2016 Jun; 52(3):427-40

23. Valea A, Carsote M, Ghervan C, Georgescu C. Glycemic profile in patients with acromegaly treated with somatostatin analogue. J Med Life. 2015; 8 Spec Issue:82-6.

24. Pekic S, Popovic V. Diagnosis of endocrine disease: Expanding the cause of hypopituitarism. Eur J Endocrinol. 2017; 176(6):R269-R282.

25. Geller JL, Braunstein GD. Dermatologic manifestations of hypopituitarism. Clin Dermatol. 2006; 24(4):266-75.

26. Ferraù F, Albani A, Ciresi A, Giordano C, Cannavò S. Diabetes Secondary to Acromegaly: Physiopathology, Clinical Features and Effects of Treatment. Front Endocrinol (Lausanne). 2018 Jul 6;9:358.

27. Lima AL, Illing T, Schliemann S, Elsner P. Cutaneous Manifestations of Diabetes Mellitus: A Review. Am J Clin Dermatol. 2017; 18(4):541-553.

28. Valea A, Ghervan C, Carsote M, Morar A, lacob I, Tomesc F, Pop DD, Georgescu C. Effects of combination therapy: somatostatin analogues and dopamine agonists on GH and IGF1 levels in acromegaly. Clujul Med. 2015;88(3):310-3

29. Vergès $B$. Effects of anti-somatostatin agents on glucose metabolism. Diabetes Metab. 2017; 43(5):411-415.

30. Silverstein JM. Hyperglycemia induced by pasireotide in patients with Cushing's disease or acromegaly. Pituitary. 2016; 19(5):536-43. 
31. Hannah-Shmouni F, Trivellin G, Stratakis CA. Genetics of gigantism and acromegaly. Growth Horm IGF Res. 2016; 30-31:37-41.

32. Poiana C, Neamţu MC, Avramescu ET, Carsote M, Trifănescu R, Terzea D, Neamtu OM, Ferechide D, Danciulescu Miulescu R. The poor prognosis factors in G2 neuroendocrine tumor. Rom J Morphol Embryol. 2013; 54(3 Suppl):717-20.

33. Poiana C, Neamtu MC, Avramescu ET, Carsote M, Trifanescu R, Terzea D, Neamtu OM, Danciulescu Miulescu R. The dedifferentiation of neuroendocrine tumor metastases: Myth or reality? Rom J Morphol Embryol. 2013; 54(1):201-3.

34. Poiana C, Carsote M, Ardeleanu C, Terzea D, Avramescu ET, Neamtu MC, Miulescu RD. The value of the immunohistochemistry in a case of gastric neuroendocrine tumor and thyroid metastasis. Rom J Morphol Embryol. 2011; 52(1):187-92.

35. Buzzola R, Kurukulasuriya LR, Touza M, Litofsky NS, Brietzke S, Sowers JR. A Possible New Multiple Endocrine Neoplasia Mutation in a Patient with a Prototypic Multiple Endocrine Neoplasia Presentation. Cardiorenal Med. 2016; 6(2):129-34.

36. Jouinot A, Bertherat J. Diseases Predisposing to Adrenocortical Malignancy (Li-Fraumeni Syndrome, Beckwith-Wiedemann Syndrome, and Carney Complex). Exp Suppl. 2019; 111:149-169.

37. Poiana C, Carsote M, Chirita C, Terzea D, Paun S, Beuran M. Giant adrenal cyst: Case study. J Med Life 2010; 3(3):308-313.

38. Cuny T, Mac TT, Romanet P, Dufour H, Morange I, Albarel F, Lagarde A, Castinetti F, Graillon T, North MO, Barlier A, Brue T. Acromegaly in Carney complex. Pituitary. 2019 ;22(5):456-466.

39. Spencer T, Pan KS, Collins MT, Boyce AM. The Clinical Spectrum of McCune-Albright Syndrome and Its Management. Horm Res Paediatr. 2019: 1-10.

40. Anderson S. Café au Lait Macules and Associated Genetic Syndromes. J Pediatr Health Care. 2020; 34(1):71-81. 